3. Slight but perfectly healthy discharge on the outer side, but in all respects going on favourably.

10. Stump nearly all healed; she is perfectly well in health, enjoying the more generous diet she was ordered a few days back.

20. I will not take up more of your valuable space than to say that the girl is quite well, and goes out every day. I may, however, remark, that $I$ think the case interesting as illustrative of the great extent to which you you may go in young persons, when the precaution is taken of carefully watching the lungs.

1, Broad Sanctuary, Westminster.

\section{"CURVATURE OF THE RADIUS WITHOUT FRACTURE."}

\section{To the Editor of THE Lancet.}

Sir,-Having read a communication from Dr. Mantell, on partial fractures of the radius with curvature, in your Journal of the 11th instant, and also two letters in your Journal of the 25th instant, $I$ beg to mention that $I$ have had several cases of a similar description, as regards external appearances, which have occurred during a practice of nearly fourteen years, and which $I$ call curvature without fracture. I have had both the ulna and radius, and the radius alone injured; and in one case the tibia in an infant 9 or 10 months old from a fall, and in the same child in a few days afterwards the ulna and radius from being carelessly taken up by the arm; it has always occurred in children. I have always considered and treated them simply as curvatures of the bones resulting from a softened state; for at the period of life at which it occurs, the bones are sometimes soft enough to bend without breaking; a tough twig will oftentimes, by bending, crush on the concave side, without a fracture on the convex, and yet remain permanently curved. I have usually applied splints and cold applications, and, by keeping up a moderate pressure by means of the tapes round the splints, found in a week or ten days the limb to have regained its natural state, and able to be used. The reason I would give in support of my opinion, is the absence of any formation of callus, which must, I conceive, be formed in every instance of fracture of the bones of which I am speaking. On referring to the "Cyclopædia of Anatomy and Physiology," Part 5, page 438, Dr. Benson says,-

"In early life, when the animal material preponderates in quantity, the bones are highly vaseular, and comparatively soft, fiexible, and springy, and though liable to many serious diseases, they are very apt to escape the effects of injury. Fracture is uncommon in infancy and in childhood; the bones bending rather than breaking, often exhibit that partial fracture which has been likened to a "branch of a tree that yields to an attempt to break it, while it still retains its sap." This I consider bears out my opinion on the above cases. Your obedient servant,

Hounslow, Sept. 27, 1841.

\section{R E M A R K S}

OP

\section{MR. BODINGTON ON THE LETTER OF “ A LOOKER-ON."}

\section{To the Editor of The LANCET.}

Sir,-By your favour I have a few remarks to offer in answer to the long letter of "A Looker-on," in The Lancet of September 18, a large portion of which consists of gross personalities levelled at me, and as coming from one wearing a mask, the readers of The Lancet will, I feel assured, appreciate it as it deserves. If $I$ have succeeded somewhat in setting right the questions discussed for the public advantage, at the expense of some personal abuse, I shall hold it cheap indeed. Your readers will not fail to cull from the verbose epistle of "A LOoKeRon," the following admissions :-First, "that the working of the moral system may exist in an asylum of comparatively few inmates ;" secondly, and as a consequence of the adoption of this principle, he recommends to the counties of Gloucester and Hereford to remove their wealthy from the pauper patients into a distinct establishment, that they may have the advantage arising from a smaller society. Here, then, "A LOOKER-on" himself confirms the opinions I expressed in my former letter.

Your correspondent "A Looker-on" labours hard to make it appear that $I$ alluded only to large licensed private asylums, and not to county asylums, when speaking of abuses in treatment which had come to my knowledge in my last letter; but your readers will recollect that $I$ spoke distinctly of county asylums only where gross abuses had existed, and $I$ know of no particular instances of abuse in private licenged houses, further than what has of necessity arisen from the too great mingling together of masses of lunatics in one house, and from the necessary delegation of authority over them in that case to serving-men and women : and I repeat, in these large communities nothing is known of the system so commonly practised in the smaller institutions of receiving a patient as a visitor, or a friend, and practising upon him the praiseworthy deceit that he is come to take up with you a temporary abode for the benefit of his health, and thus, in fact, he may come and go, and never be aware (in many instances this occurs) that he has been in an asylum at all. Can this be done in large county asylums, where everything is formal, cold, and forbidding, too much in the barrack style, splendid, no doubt, in some instances, 